\title{
Drug Therapy Management of Cardiovascular Disease patients admitted to intensive Care units of Tertiary care Hospitals
}

\author{
Prajapati Aarohi Ashokbhai*, Deshpande Shrikalp \\ Department of Clinical Pharmacy and Pharmacology, KBIPER, Gandhinagar-382023 Gujarat, INDIA.
}

\begin{abstract}
Background: Therapy in Intensive Care Unit (ICU) often involves poly pharmacy and patients require close therapy monitoring. When individualization of therapy is warranted, the role of pharmacist can prove to be the best in achieving the therapeutic goals and improve the treatment outcomes of the patients. Method: A prospective, observational study was carried out in the medical ICU of a tertiary care hospital for a period of three months. Results: A total of 100 cardiovascular disease patient files were selected and data collected was analysed for the drug therapy management. Medication prescribed was analysed using advance medication review. The mean (SD) age was found to be 58.4 (10.4) years. $65 \%$ were male and $35 \%$ were female patients with a mean (SD) of 13.49 (5.62) medicines administered per patient. A total of 174 drug related problems were identified during the study period, which were classified into drug interactions $86 \%$ (p-value 0.953 ), untreated indications $23 \%$ ( $p$-value 0.727 ), adverse drug reactions $22 \%$, improper drug selection $18 \%$ (p-value 0.431 ), therapeutic duplication $15 \%$ (p-value 0.431), patient in need of TDM $6 \%$ and drug without indication $4 \%$ ( $p$-value 0.917 ). Among 100 patients $77 \%$ patients received correct therapy. Conclusion: The study showed that medication management of critically ill patients can decrease drug related problems in complex therapy as well improve the therapeutic outcome of the treatment.
\end{abstract}

Key words: Cardiovascular diseases, Drug Therapy Management, Drug related problems, Intensive care unit, Hospital Stay, Pharmacist Remarks.

\section{INTRODUCTION}

Role of pharmacist in Drug therapy Management (DTM) can prove to be the best to achieve therapeutic goals in patients and improves treatment outcomes by effective drug use and patient safety. ${ }^{1,2}$ Advancements in diagnostic testing, technological interventions and pharmacotherapy provides great benefits to patients with life-threatening acute illness. ${ }^{3}$ The complexity and intensity of care required by ICU patients is also associated with greater risks. ${ }^{4}$ ICU clinicians are faced with making many important drug dosing decisions each day, even when the correct medication is chosen ${ }^{5}$ although, few drug related problems (DRPs) are not preventable as they are un-predictable because of their idiosyncratic nature. ${ }^{6}$ Complex pharmacotherapy, simultaneous use of drugs incritically ill patients in ICU often require close monitoring as their safety is of paramount importance. ${ }^{7-9}$

Raising health care costs, combined with decrease in medical care formulas for hospitalized patients have focused on transitions of care and preventing readmission. DTM help patients get the most benefit from their medications by monitoring their treatment. ${ }^{10}$ Desired outcomes of DTM are appropriate drug use, enhanced patient understanding of appropriate drug use, increased patient adherence, reduced risk of adverse effects (AEs) associated with drugs, and reduced need for other costly medical services. ${ }^{1,11}$

Hence, the current project was designed to monitor the current practice of clinicians
Submitted date :02-Mar-2015 Accepted date :30-Mar-2015 DOI: $10.5530 /$ ijopp.8.1.4

Address for correspondence: Miss. Aarohi Prajapati, M. Pharm Clinical Pharmacy, Department of Clinical Pharmacy and Pharmacology, KBIPER, Gandhinagar-382023 Gujarat, INDIA.

E-mail:aar_p2408@yahoo. com

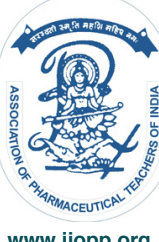




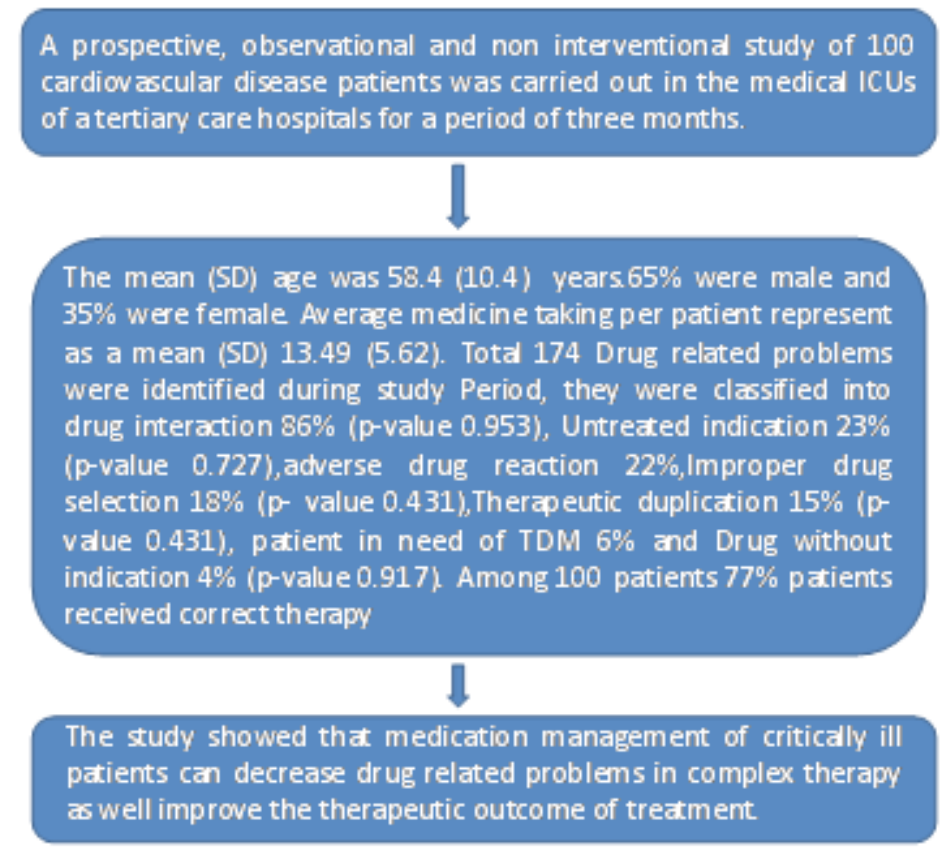

Graphical Abstract

for treatment of critically ill cardiac patients in Intensive Care Unit. Findings from this study provide a benchmark at local and state level. The results also help to monitor the progress and to identify opportunities for strategic initiatives and policies at a local and state level to improve practice.

\section{MATERIALS AND METHOD}

A prospective, observational study was carried out in the medical ICUs of two tertiary care hospitals in Ahmedabad city for a period of three months. The study has been passed from an independent ethics committee. A total of 100 cardiovascular disease patient's files were screened and data was analysed for DTM. Only patient files were studied for the research purpose which were selected randomly and no patient was included in the study as such.

Patient files were screened for the demographic information, diagnosis, laboratory details and the medication prescribed each day. The medications prescribed to the patients were analysed by means of advanced medication review form. After performing advanced medication review, results ${ }^{12}$ were classified into drug related problems in several categories like, untreated indications, drug interactions, adverse drug reactions, patient in need of therapeutic drug monitoring, drug without indication, improper therapy, therapeutic duplication.

Both male and female patients with cardiovascular disease admitted to ICU were selected who had age of 30 years or more. The files were reviewed until patient got discharged or expired. Pregnant women, nursing mothers, patients shifted to other wards of the hospital were excluded from follow-up.

\section{Statstical analysis}

Collected information was analysed using Microsoft Office Excel 2007 and statistical software SPSS. Descriptive data analysis has been performed in the form of frequency and percentage of demographic variables and drug related issues and shown as various tables and graphs for better understanding of comparison of both the centers.Non-parametric test used was chi square test with yates correction for p-values.

\section{RESULTS}

A total of 100 patients were enrolled in the study, of which 60 patients were of government hospital and 40 from private hospital. Majority of the patients were male $\mathrm{n}=65(65 \%)$ and $\mathrm{n}=35(35 \%)$ were female and the average age of the patients admitted to ICU was $58.43 \pm$ 10.84 (mean $\pm \mathrm{SD}$ ) years. The average number of drugs received by the ICU patients was 15.3 per patient. The average days of hospitalization stay in Government hospital was 5.4 days and 4.45 days of the private hospital.

Among admitted patients, 51-60 years aged patients were frequently found which proves that chronic conditions are prevalent in this age group. They were receiving a mean (SD) of 13.49 (5.62) medications. 51\% patients were having co morbidities mostly with Diabetes mel- 


\begin{tabular}{|c|c|c|c|}
\hline Variable & Total & government (60) & private site (40) \\
\hline \multicolumn{4}{|c|}{ Indication (no of patients (\%)) } \\
\hline Untreated indication & $23(23 \%)$ & $18(30 \%)$ & $5(12.5 \%)$ \\
\hline Drug without indication & $4(4 \%)$ & $3(5 \%)$ & $1(2.5 \%)$ \\
\hline \multicolumn{4}{|c|}{ Safety (no of patients (\%)) } \\
\hline ADR & $22(22 \%)$ & $15(25 \%)$ & $7(17.5 \%)$ \\
\hline DI & $85(85 \%)$ & $51(85 \%)$ & $35(87.5 \%)$ \\
\hline Major & $51(51 \%)$ & $6(10 \%)$ & $9(22.5 \%)$ \\
\hline Moderate & $14(14 \%)$ & $33(55 \%)$ & $18(45 \%)$ \\
\hline Minor & $20(20 \%)$ & $12(20 \%)$ & $8(20 \%)$ \\
\hline Therapeutic duplication & $15(15 \%)$ & $6(10 \%)$ & $7(11.6 \%)$ \\
\hline \multicolumn{4}{|c|}{ Effectiveness (no of patients (\%)) } \\
\hline Improper drug selection & $18(18 \%)$ & $14(23.33 \%)$ & $4(10 \%)$ \\
\hline $\begin{array}{c}\text { Need of TDM (Sodium } \\
\text { valproate, LMWH, } \\
\text { Atropin, Digoxin, NA, } \\
\text { ACEI) }\end{array}$ & $6(6 \%)$ & $5(8.33 \%)$ & $1(2.5 \%)$ \\
\hline \multicolumn{4}{|c|}{ Outcome (no of patients (\%)) } \\
\hline $\begin{array}{l}\text { Transferred to other } \\
\text { wards }\end{array}$ & $60(60 \%)$ & $50(83.33 \%)$ & $10(25 \%)$ \\
\hline $\begin{array}{c}\text { Discharged (from the } \\
\text { hospital) }\end{array}$ & $33(33 \%)$ & $5(8.33 \%)$ & $28(70 \%)$ \\
\hline Expire & $7(7 \%)$ & $5(8.33 \%)$ & $2(5 \%)$ \\
\hline \multicolumn{4}{|c|}{ Pharmacist remarks (no of patients (\%)) } \\
\hline Correct therapy & $77(77 \%)$ & $41(68.3 \%)$ & $36(90 \%)$ \\
\hline Improper therapy & $23(23 \%)$ & $19(31.66 \%)$ & $4(10 \%)$ \\
\hline
\end{tabular}

\begin{tabular}{|c|c|c|}
\hline Drug Related Problems & Chi Square Value & $P$ value \\
\hline Untreated indication & 3.221 & 0.727 \\
\hline Drug without indication & 0.011 & 0.917 \\
\hline Drug interaction & 0.003 & 0.953 \\
\hline Therapeutic duplication & 0.623 & 0.431 \\
\hline Improper therapy & 0.623 & 0.431 \\
\hline
\end{tabular}

litus and COPD. During the study period, major cardiovascular diseases observed were is chemic heart disease $(20 \%)$ and cardiovascular stroke $(12 \%)$, in government hospital patient were of HT $(18 \%)$ frequently found and in private centre the mostly diagnosed disease was Ischemic heart disease (15\%).

A total of 174 drug related issues were identified during the study period. Non-parametric test chi-square test with Yates correction (Table 1) was applied to evaluate drug therapy problems to find (Table 2) out the p-values of drug related problem in drug therapy management.

\section{DISCUSSION}

Clinical pharmacy services have made a positive impact on health care system. ${ }^{13}$ Many studies were conducted to evaluate the value addition of clinical pharmacy services into the patient care in critical care setting but cardiovascular disease patient were rarely focused ${ }^{14}$ as the chances of readmission in hospitals and no of days of hospitalisation is found more in cardiac ill patient so this study aimed to focus on drug therapy management of cardiovascular disease patients in ICU. A drug therapy plan may require discontinuation or addition of a drug as well dosage adjustments, and thus requires more complex decision making skills. Determining whether a patient actually requires drug therapy is probably the most complex problem to identify because the clinical pharmacist must integrate everything they know about the patient's drug therapy and patient's social history as well pathophysiology and pharmacotherapeutics. ${ }^{15}$ Drug therapy management is an effective mechanism to facilitate assessment of the indications, effectiveness, and safety of drug products, especially in patients who are using multiple medications. ${ }^{16} \mathrm{~A}$ number of studies have shown that many hospital admissions are due to adverse drug events, medication errors or sub-optimal prescribing. ${ }^{17}$ Hence, this study supports the concept of medication therapy management provided to patients to improve therapeutic outcome. 


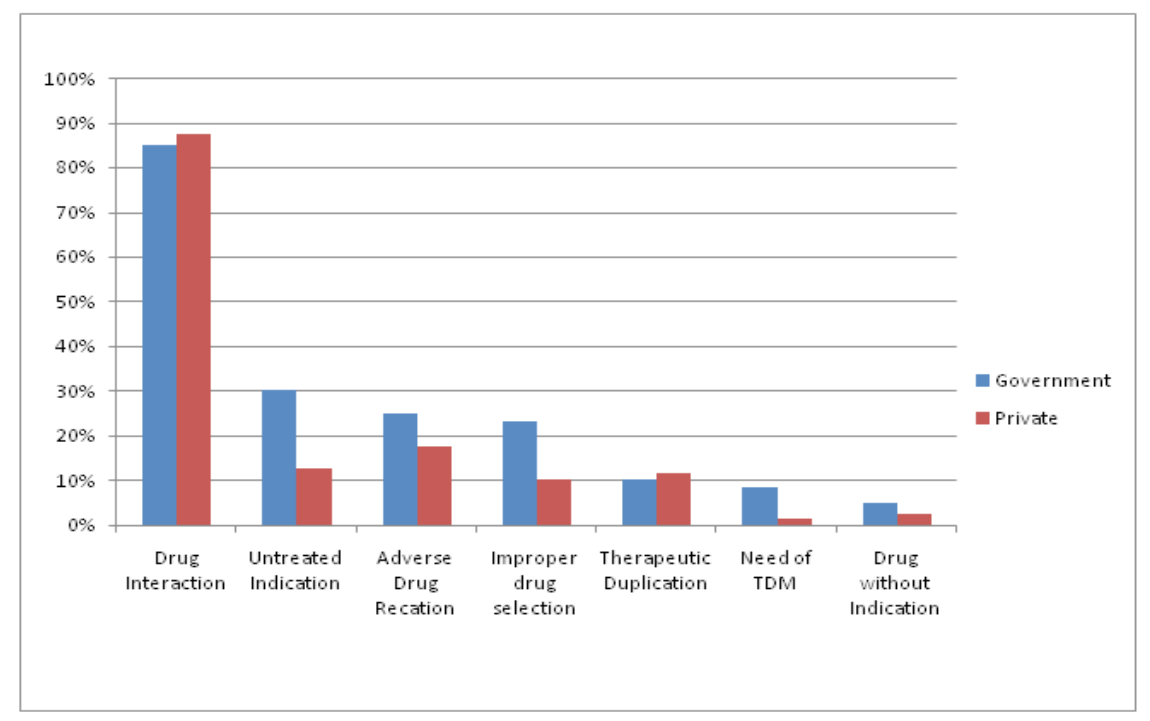

Figure 1: Drug related problems in Government and Private Hospital

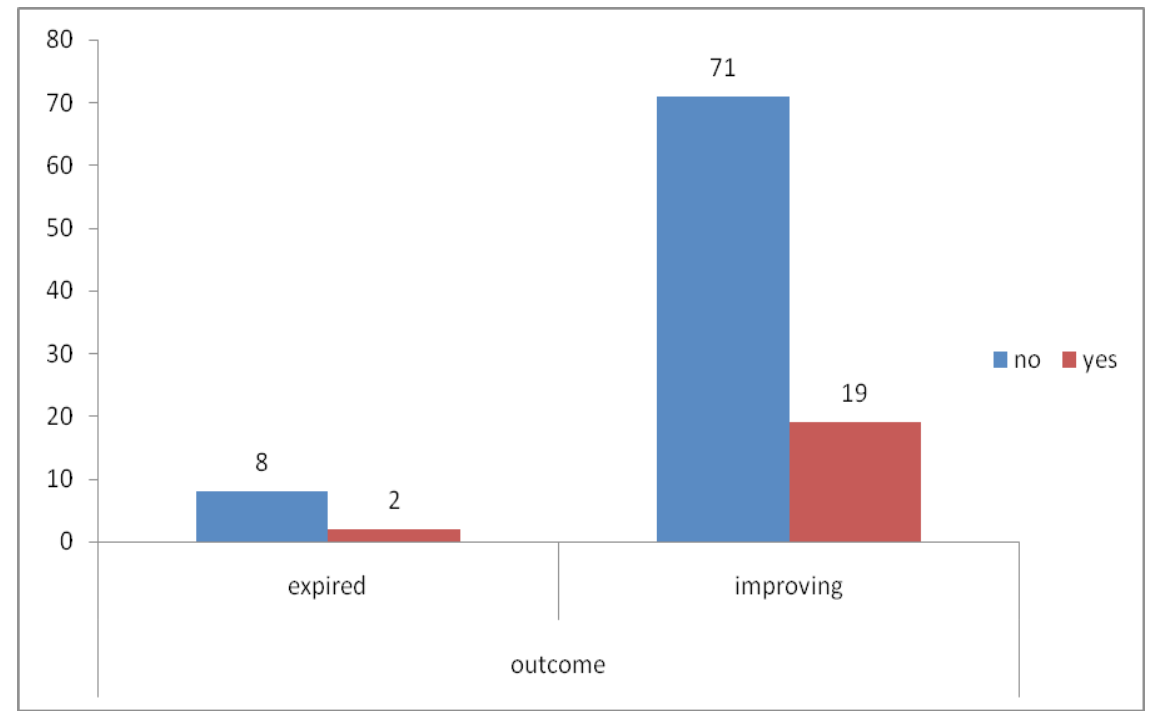

Figure 2: Untreated indication and outcome of hospital stay

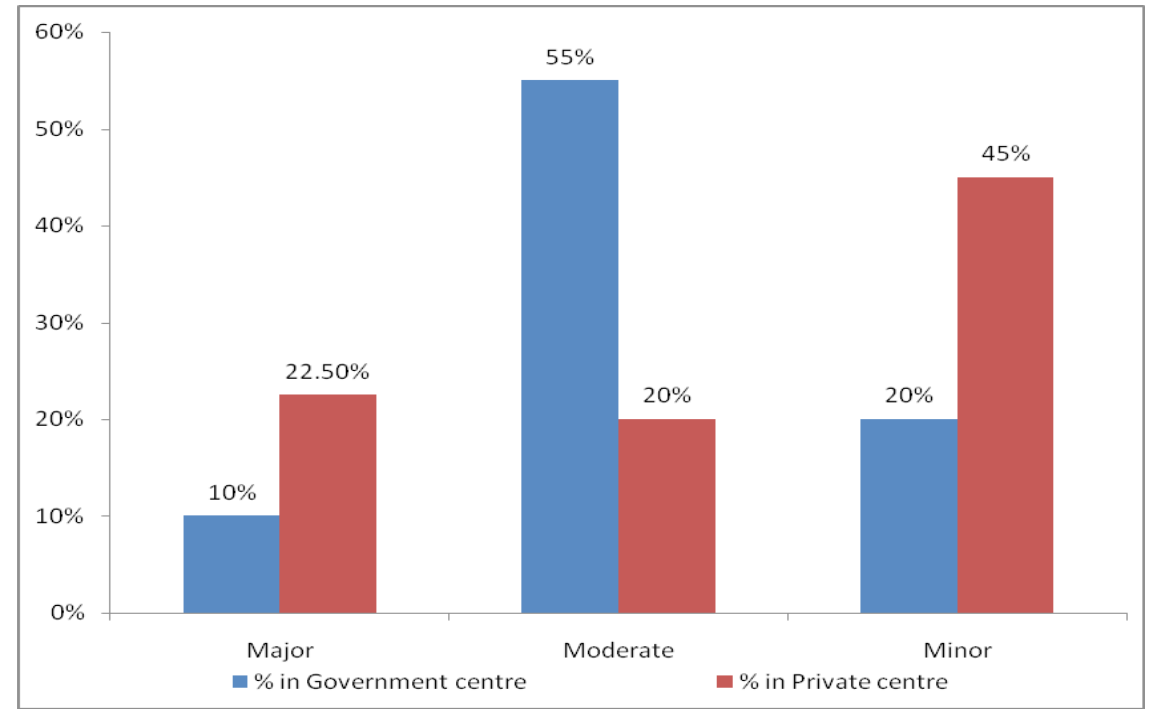

Figure 3: Percentage of Drug interaction in Government and Private Hospital 
Study result shows that male patients admitted were more compared to female and may infer that male are more prone to cardiac diseases compare to female gender. Average age of patients found was between 50-70 years, which indicates that the cardiac conditions found may be chronic in this age group.

Hospital stay in ICU was more in government centre as compare to private hospital. During the study period more prevalence of ischemic heart disease and hypertension were found among all cardiac patients. Among all admitted patients in ICU for cardiac problems, patients were suffering mostly from co-morbid conditions and commonly found co-morbid condition was diabetes mellitus, which supports the study that DM patients are more prone to high risk of cardiac complications.

Drug prescribing pattern shows that patients admitted to private hospital received more medicines than the government centre, but the treatment was not unsafe altogether.

A total of 174 drug related problems were identified, out of which $86 \%$ drug interactions (DIs) were found (Figure 1) in the treatment of both hospitals. When evaluating DIs, one primary concern was the clinical significance or level (Figure 3) of severity of the interaction. Even though many DIs were identified in this study, only a few were clinically significant $(20 \%)$ out of which most required monitoring the patients (55\%). It can be due to more number of drugs prescribed to patients, as well as therapeutic duplications or supplemental medicines. ${ }^{18,19}$ Major DIs were found between phenytoin + Furosemide, Furosemide + Potassium chloride, metronidazole + furosemide. Even though DIs were identified, treatment was not stop pedas in most of the cases, the drug was absolutely necessary for the patient and the benefits of drug therapy outweighed the risk posed by the DI. Moderately severe drug interactions were found more in government centre and prevalence of major drug interactions were found more in private hospital, both needs to be taken in consideration for treatment of critically ill patients. It was observed that at ICU checking of DI was not in practice. Pharmacist as a healthcare member can help check DIs in better drug therapy management. Untreated indications in patients were found more in government hospital (Figure 2) which can be one of the reasons for longer ICU stay. Drug without indication was also found more in the government centre which adds chances of drug safety issue.

Our data shows that prevalence of ADRs was more in government ICU, which may directly affect the outcome of treatment and ICU stay. But studies report that monitoring high risk medications and abnormal labora- tory value changes that require dosage adjustment can reduce potential ADRs and improve clinical outcome among hospitalised patients. ${ }^{20}$ In our study dermatological ADRs were commonly observed.

Treatment outcome shows that majority of the patients were directly discharged from the ICU in private hospital where patients were mostly transferred to other wards to stabilize in government centre. Number of patients expired were more in government hospital compared to private centre, which reflects the treatment outcome of admitted patients.

We observed that patients admitted to the government hospital and private hospital does not have great differences in the rate of occurrence of drug therapy problems. Ours is the first of its kind of study to compare the drug therapy management in two Intensive care units of tertiary care hospitals in Gujarat state, which shows the difference in therapy but both the centres show the same level of facilities for patients. Well trained clinical pharmacists play a significant role in ICU for the better treatment out comes in critically ill patients by deciding correct doses of medications. As pharmacy practice continues to evolve with a greater focus on medication therapy management it becomes more important for patients in $\mathrm{ICU}^{21,22}$ as they require an extra amount of care and consideration as a consequences of complicated and extensive medication regimens. ${ }^{23}$ So, comparison of two centres gave us basic idea about the differences in treatment practices of healthcare team by finding out prevalence of drug related problems and individualisation of therapy in ICU.

\section{Limitations of the study}

The external validity of the study may have also been limited by the small sample size, short study duration and follow-up. This is the first type of attempt to provide drug therapy management in our setting. Monitoring patients for longer period would reflect more accurate profile of the natural time frame of the medication views. Also, this study includes the patients of cardiovascular disease only. Other chronic diseases can also be managed in a similar manner. This study does not include intervention part which could have been very useful for the patients as well as healthcare providers. Patients and patient party were not included in the study, if included more specific information could have been collated for sound research. Based on valid property \& with proper statistics, this study could have been done with large sample size. Patients with cardiovascular diseases, were mostly admitted to ICCU (Intensive Critical Care Unit) but not to ICU. In our study, we have considered ICU as common. 


\section{Future scope of the study}

This study may be helpful in identifying the new concept of drug therapy management of patients in different disease conditions in critical care and also introduce the new concept of drug therapy management in Gujarat state. Cost evaluation of medication therapy under same title can also be performed for critically patients for avoiding unnecessary costing of medication.

\section{CONCLUSION}

Drug therapy management (DTM) has useful and positive impact on critically ill patients in ICU. More individual care is required for cardiovascular disease patients admitted into ICU so, DTM can prevent or minimize the drug related problems, and improve the therapeutic outcomes of critically ill patients. Role of clinical pharmacist proves significant in ICU for Drug Therapy management of cardiac ill patients.

\section{CONFLICT OF INTEREST}

There is no conflict of interest in the study.

\section{ACKNOWLEDGEMENT}

Dr. Chirag patel, HOD, Department of emergency and Trauma,Intensive care unit Civil Hospital, asarva, Ahmedabad.

\section{Highlights of Paper}

- Made a clear attempt to show the general prescribing pattern of physicians in bronchial asthmatic paediatric patients.

- Impact of pharmaceutical care was evaluated and shown how significant the impact was.

- Pharmaceutical care is provided and emphasized its importance in pediatric patients.

\section{Author Profile}

- Miss Aarohi Prajapati: working as a Medical Writer(writing on Diabetes research) in Ahmedabad, Gujarat. She has recently completed masters in clinical pharamacy (2014).She has one given various posters presentation, Power point presentation and one research paper during her academic years.

- Dr.Shrikalp Deshpande: He is Professor and Head (Pharmacology and Clinical Pharmacy)He has done M.Pharm(Phamracology), DBM, MMS(Marketing), LL.B(Gen), Ph.D. He has published various research and review papers in journals and he is involved in various activities of pharmacy practice, pharmacology and drug regulatory affairs. He is also member of reputed institutes.

\section{REFERENCES}

1. Melissa SM, Susan MM, Wendey DH, Daucan LH, Jean-venable RG. Medication Therapy Management: Its relationship to patient Counselling, Disease management, and Pharmaceutical Care. J Am Pharm Assoc. 2007; 47(5): 620-8.

2. Jayesh MK, Bhagya MS, Parth MD, Sumit PP. A Study of Adverse Drug Reactions In Patients admitted to Intensive Care Unit of a tertiary care teaching rural hospital. Int J Pharm Pharm Sci. 2012 November 16; 5: 160-3.

3. Reis AMM, Cassiani SHB. Prevalence of potential drug interactions in patients in an intensive care unit of a university hospital in Brazil. Clinics 2011may 3; 66(1): 9-15.

4. Mitchell IA, Antoniou B, Gosper JL et al. A robust clinical review process: the catalyst for clinical governance in an Australian tertiary hospital. MJA 2008 october; 189(8): 451-5.

5. Devlin JW, Barletta JF. Principles of Drug Dosing in Critically III Patients chapter 21 Part I Critical care procedures, Monitoring, and Pharmacology; springer; 9-13.

6. Lucca JM, Ramesh M, Narahari GM, Minaz N. Impact of clinical pharmacist intervention on the cost of drug therapy in intensive care units of a tertiary care teaching hospital. J Pharmacol Pharmacother. 2012; 3: 242-7.

7. Jillmarie K, Yanchik. Implementation of a drug therapy monitoring clinic in a primary care setting. Am J Health-syst Pharm. 2000 (12); 15(4): 30-34.

8. Todi SK. Quality Indiactors In Critical Care: Patient Safety. Indian J Crit Care Med. 2009 Oct-Dec; 13(4): 173-206.

9. Philip D, Walson. Therapeutic drug monitoring in special populations Clinical Chemistry 1998; 44: 2 415-9.

10. Audrey JM, Micheal TS, Colleen MR, Todd DS. Maximizing Medication Therapy Management services through a referral initiative. Am J Health-Syst Pharm. 2012 July; 69: 1234-9

11. Parthasarthi G. Drug Therapy Review. A text Book of Clinical Pharmacy Practice-Essential Concepts and Skills. 2012; (2): 218-35.
12. A guide To Patient Medication Review-Northern Health and Social services Board; September 2003

13. Rasmussen M, Struck PA. Pilot study of pharmacist initiated interventions in drug therapy in an Australian pediatric hospital. EJHP 2007; 13: 105-12.

14. Task force on position paper on Critical care pharmacy service, Society of Critical Care Med and American Collage of Clinical Pharmacy. Position paper on Critical care pharmacy services. Pharmacotherapy 2000; 20: 1400-6.

15. John R, Micheal JM, Carrie K, Sally H, Karly H, Erin M. A guided Interview Process to Improve student Pharmacist' Identification of Drug Therapy Problems. Am J Pharm Educ. 2011 February 10; 75(1): 16.

16. Oliveira DM. Medication Therapy Management: 10 Years of Experience in a Large Integrated Health Care System. J Manag Care Pharm. 2010; 16(3): 185-95.

17. Micheal JD, Karen MA, Christopher JD, Kristen JG, George RT, Jennifer B, Dianne LC.A Prospective multicentre study of Pharmacist initiated changes to drug therapy and patient management in acute care government funded hospitals. Br J Clin Pharmcol 2003; 57(4): 513-21.

18. Alsultan MS. et al. Hospital pharmacy practice in Saudi Arabia: Drug monitoring and patient education in the Riyadh region. Saudi Pharm J. 2012 december; 1-9.

19. 19.Priyanka TP, Bharani MK, Seeba V, Dixon T, Laura S, Alvarez-U. An interventional study on intensive care unit drug therapy assessment in a rural district hospital in India. J bclinpharma. 2013; 4(3): 64-7.

20. American Society of Health-System Pharmacists. Product Details. Available from: http://store. ashp.org/Default.aspx?TabId=216andProductId=4750

21. Smith M. Pharmacists' role in improving diabetes medication management. J Diabetes Sci Technol Online 2009; 3: 175-9.

22. Pichala, et al. An interventional study on intensive care unit drug therapy assessment in a rural district hospital in India. Journal of Basic and Clinical Pharmacy 2013; 4(3): 64-7.

23. Yeolekar ME, Mehta S. ICU Care in India-Status and Challenges. JAPI. 2008; 56: 221-2.

Indian Journal of Pharmacy Practice, Vol 8, Issue 1, Jan-Mar, 2015 